\title{
Sustainable Design of a Near-Zero-Emissions Building Assisted by a Smart Hybrid Renewable Microgrid
}

\author{
Mostafa Esmaeili Shayan, Gholamhassan Najafi1,*, Barat Ghobadian¹, Shiva Gorjian¹, \\ Mohamed Mazlan²*
}

\author{
${ }^{1}$ Department of Mechanical and Biosystems Engineering, Tarbiat Modares University (TMU), Tehran, Iran. \\ ${ }^{2}$ Advanced Material Research Cluster, Faculty of Bioengineering and Technology, University of Malaysia Kelantan, Jeli, Kelantan, \\ Malaysia
}

\begin{abstract}
Renewable energy regulations place a premium on both the use of renewable energy sources and energy efficiency improvements. One of the growing milestones in building construction is the invention of green cottages. Building Integrated Photovoltaic (BIPV) technologies have been proved to aid buildings that partially meet their energy demand as sustainable solar energy generating technologies throughout the previous decade. Curved facades provide a challenge for typical photovoltaics. This study designed, produced, and assessed elastic solar panels supported by flexible photovoltaic systems (FPVS) on a $1 \mathrm{~m} 2$ layer. The LabVIEW program recognizes and transmits online data on warm and dry climates. The fill factor was $88 \%$ and $84 \%$, respectively, when installed on the silo and biogas surfaces. The annual energy output was $810 \mathrm{kWh}$ on a flat surface, $960 \mathrm{kWh}$ on a cylindrical surface, and $1000 \mathrm{kWh}$ on a hemisphere surface. Economic analysis indicates that the NPV at Flat surface is $\$ 697.52$, with an IRR of $34.81 \%$ and an 8.5 -year capital return period. Cylindrical surfaces and hemispheres both get a $\$ 955.18$ increase. For cylindrical and hemispheric buildings, the investment yield was $39.29 \%$ and $40.47 \%$, respectively. A $20 \%$ increase in fixed investment boosted the IRR by $21.3 \%$ in the flat system. While the cylindrical system had a $25.59 \%$ raise, the hemisphere saw a $24.58 \%$ gain.
\end{abstract}

Keywords: Green Cottages; Building Integrated Photovoltaic; Sustainable; Flexible Photovoltaic Systems; LabVIEW

Article history: Received: $2^{\text {nd }}$ Jan 2022; Revised: $8^{\text {th }}$ February 2022; Accepted:15 ${ }^{\text {th }}$ February 2022; Available online: $25^{\text {th }}$ February 2022 How to cite this article: Esmaeili Shayan, M., Najafi, G., Ghobadian, B., Mazlan, M. (2022) Sustainable Design of a Near-Zero-Emissions Building Assisted by a Smart Hybrid Renewable Microgrid. International Journal of Renewable Energy Development, 11(2), 471-480 https://doi.org/10.14710/ijred.2022.43838

\section{Introduction}

The Kyoto Protocol is an international agreement related to the $\mathrm{UN}$ on climate change, which requires countries worldwide to set specific carbon reduction targets around the world. The main concern of environmental policymakers is climate change mitigation. The impact of various factors on GHG emissions has been studied by many authors (Liobikienè et al., 2021). Despite supply chain issues and construction delays caused by the pandemic, renewable capacity additions in 2020 increased by over $45 \%$ from 2019. Global wind capacity additions increased by $90 \%$. Also underpinning this record growth was the $23 \%$ expansion of new solar PV installations to almost 135 GW in 2020 (Jäger-Waldau, 2021). Utility-scale applications will account for about $70 \%$ of annual PV additions by 2022 , up from $55 \%$ in 2020 . Although China's significant FITs for commercial and industrial PV projects increased the ratio of distributed projects from $25 \%$ in 2016 to nearly $45 \%$ in 2018 , this trend reversed in 2019 (IEA, 2021). In the last decades, photovoltaic (PV) technology has been drawing enormous attention worldwide. In the future, solar energy consumption is expected to increase due to further reductions in prices in solar cell technology (Braito et al., 2017; Hasanien, 2018). Aside from the nonlinear nature and environmental dependability of PV systems, the conversion of energy by PV panels is undesirable (Skordoulis et al., 2020). It is a positive step towards obtaining energy from light through the advancement of science. Thanks to further cost reductions and continuous policy support from 120 governments globally, PV capacity additions are forecast to expand to 162 GW in 2022 (O'Shaughnessy et al., 2021; Tsantopoulos et al., 2014). Despite the ongoing COVID-19 pandemic, the overall investments in solar energy increased by $12 \%$ to USD 148.6 billion (EUR 125 billion). In 2020, over $135 \mathrm{GW}$ of new solar photovoltaic electricity generation capacity was installed increasing the total cumulative installed capacity to over $770 \mathrm{GW}$ (Jäger-Waldau, 2021). The quality of electricity and the various sources of supply are now seen as the core solutions of policymakers around the world. Fossil fuels fall from almost four-fifths of total energy supply today to slightly over one-fifth (Najafi et al., 2011). Some of the most challenging environmental problems are the production and usage of oil resources and greenhouse gases. Every year, non-renewable energy

* Correspondence author: g.najafi@modares.ac.ir/ ** mazlan.m@umk.edu.my

IJRED-ISSN: 2252-4940.Copyright (C 2022. The Authors. Published by CBIORE 
releases a megatonne of greenhouse gases (GHG) into the atmosphere (Awad et al., 2017; Muhammad-Sukki et al., 2011). In South Asia, the concept of using skin-based solar systems is on the increase. BIPV is increasingly used as a primary or secondary energy source in buildings. Unique criteria for the proper efficiency of the BIPV cells need to be regarded. Building-integrated photovoltaics (BIPV) is one of the most promising contributors to net-zero energy buildings, while also increasing the aesthetic value of the built environment and Thermal and sound insulation properties (Briguglio et al., 2017). The electrical power from the solar cells is increased by reducing the operating temperature, Like all other semiconductor devices, solar cells are sensitive to temperature. Temperature increases reduce the bandgap of a semiconductor which leads to the decrease of the module efficiency and output power (Mohsen Azadbakht et al., 2015; Zeb et al., 2014). Using natural or forced ventilation systems is one of the most effective ways to lower the solar cell temperature and reduce efficiency. In addition, the solar system designer can position the solar cell in the direction of the wind at the correct position (Rabab Mudakkar et al., 2013; Shukla et al., 2018). Iran's energy intensity index is up by a factor of 3. Developing countries can be expected to find themselves in a similar position. For developed countries, this index is about 0.3 (Esmaeili Shayan, et al., 2021; Ettefaghi et al., 2018). An increasing human population and the need for energy usage, limitations and inability to react to refined petroleum products have increased the desire to use renewable energy, especially solar energy. Regardless of this, electricity demand per household has increased dramatically over 2007-2018 (Al-Falahi et al., 2019). It is expected that this growth will occur until 2030 and that the slope will reach 60 percent (Azadbakht et al., 2015). In the supply of renewable energy and considered Iran's capacity, solar energy is environmentally sustainable, leading to non- $\mathrm{CO}_{2}$ generation; it also contributes to natural resource sustainability, land recovery, reduced power transmission lines, increased regional energy control, improved speed and costeffectiveness of electricity transmission into rural areas (Solangi et al., 2011). Iran's Central Bank has reported that this sector's inflation rate was 10 percent a year based on the average inflation rate between 2011 and 2016 (Salehi-Isfahani et al., 2018). Research surveys have estimated that Tehran's sunny days and hours are about 313 days and 1742 hours a year, respectively. The increase from the southeast to the northwest of Iran is reduced, whereas it usually increases from the west to the east (Esmaeili Shayan, 2020). The irradiance map and statistical irradiance simulations show that irradiance level in clear air is theoretically high in Iran, including Yazd, Kerman, Tabas, Birjand, Iranshahr, Chabahar, Shiraz, Bam, Bushehr, and desert areas. However, building construction does not usually permit traditional solar systems with rigid modules (Esmaeili shayan et al., 2020). The flexible solar cells can generate voltages of more than $50 \mathrm{~V}$. These circuits will contain appliances voltage requiring higher setup power in normal mode (Mohsen Azadbakht et al., 2013; Chen et al., 2019). Major market trends are described as the inverter, module size, main power, and deployment and Balance of System (BOS) cost decline. With a cumulative annual growth rate of $200^{\text {th }}$ Compound (CAGR), the cost of modules is forecast to decline from 260 cents/Wp in 2009 to 30 cents/Wp in 2018
(Padmanathan et al., 2018). The building's shape directly affects its energy use. Modern architecture regularly uses curved forms. They have a significant impact on the building's solar and energy performance, and may improve the internal environment. The curved shape is also used on silos, biogas tanks, greenhouses and structures. The Taguchi factorial experiment and response surface methods are used to improve the precision of the test and reduce the expense of testing and speed up the experiment (Dehghan et al., 2021). Conventional solar panels involve the construction of glass panels that are usually not quite consistent with cylindrical geometric shapes (Keshtegar et $a l ., 2018)$. One of the solutions to these problems is the development and production of solar systems focused on flexible panels that, in addition to supporting the architecture of the desired structures and sustaining the previous capabilities, are economical and provide the energy needs of the electrical equipment for these structures (Ghritlahre et al., 2018). Rural electrification in Iran was started by using photovoltaics in 2006 (Esmaeili Shayan et al., 2020; Najafi et al., 2007). Hydrocarbons dominate Iran's energy mix. Traditional thermal power plants run on natural gas and petroleum derivatives such as gasoline and fuel oil. The remaining $2 \%$ comes from hydropower, nuclear, biofuels, and other renewables (Mat Yasin et al., 2017). Solar power plants have the least capacity of the three grid-connected power plants (wind, biogas, and solar) mounted. Wind provides the majority of renewable energy capacity $[29,30]$.

The popularity of photovoltaic technology has expanded over the previous decade due to the good consequences, the convenience of investing in photovoltaics, and the performance of photovoltaics. The research addressed a knowledge gap on the desire of certain older and historic buildings to invest in photovoltaics. Additionally, the study findings enabled greater understanding of the elements that influence investment decisions in photovoltaics.

Flexible Photovoltaic Systems are suitable for buildings with complex shape envelopes, such as harvest silos, traditional Islamic buildings, and Petrochemical Tanks. This critical phase can provide a portion of the electrical energy while preserving geometric and aerodynamic properties. This study explores the potential of a flexible solar conversion device for energy supply on curved surfaces. In this research, we used environmental assessment, and environmental approaches focused on pilot projects to use the actual capacity of a flexible solar energy conversion system.

\section{Materials and Methods}

Flexible layers with suitable depth and durability can cover any design and introduce more incredible energy with selected columns. Fig.1 illustrates the system's hardware schematic and a block diagram of the voltage control system and FPV power plant's components. The components involved in the solar energy system were modeled in flat, cylindrical, and hemispherical shapes and studied under actual conditions. Data from irradiance, temperature, humidity, wind speed were recorded every 30 minutes through the data logger and sent to LabVIEW software via USB-4711A device. A power meter measures and records the voltage, current, and output power of the systems. Throughout this process, the test layer was 
placed at $1 \mathrm{~m}^{2}$, and the analysis and design of the radial and axial shapes were taken out

The Solar power conversion model based on flexible panels, as shown in Fig. 2 includes: geometric arrangement on cylindrical, hemispheric and flat surfaces, flexible solar cell, battery block, irradiance meter, temperature sensor, humidity sensor, anemometer, voltage monitor, power amplifier, planning circuits, battery plugs and fuses, analog-digital converter. Moreover, the Ambient temperature and surface temperature of solar cells were measured using 16 complete circuits of $\operatorname{lm} 35$ sensor connected to USB4711A with $0.1 \circ \mathrm{C}$ accuracy and an Extech AN200 Wind sensor with $\pm 5 \%$ accuracy in the wind speed range of 0.4 to $30 \mathrm{~m} / \mathrm{s}$.

The amorphous silicon (a-Si) element JNsolar3W-12v with three deposition junction points in a stainless polymer sheet and a lock diode has been used to resist the leakage of the battery current to the solar module panel (Bloem et al., 2012). The most efficient matching layer provided by choice of $1 \mathrm{~m} 2$ solar panels could be $9744 \mathrm{~cm} 2$. After removing the edges of the flexible solar panel, the photovoltaic section will be equal to $6996 \mathrm{~cm}^{2}$. To cover the cylindrical and hemispherical surfaces with a specified area, 16 flexible solar elements, a cylindrical and hemispherical structure with a particular area is required. The structural models were created in SketchUp and the thermal stress analysis in Ansys Workbench showed a maximum strain of $0.041 \mathrm{~mm}$ in the radius direction. The strain was negligible, but to avoid rupturing the flexible parts, the contact distance was set at $2 \mathrm{~mm}$. The RS232 device and the LabVIEW software package were used to attach the temperature module. The Fill factor (FF) is a parameter that, in conjunction with Voc and Isc, determines the maximum power from a solar cell. The FF is defined as the ratio of the maximum power from the solar cell to the product of Voc and Isc. The matching principle is quantitatively similar to the current-voltage supply series, and the higher the amount, the greater the photovoltaic system's output. The fill factor is calculated on the surface according to equation (1) (Abdolbaqi et al., 2016; Yan et al., 2015). The efficiency of a photovoltaic system is also one of the most critical external measurement items. Efficiency (n) is defined by Equation (2) (Ghasemzadeh et al., 2020).

$$
\begin{aligned}
& \mathrm{FF}=\frac{V_{M P P} \times I_{M P P}}{V_{o c} \times I_{S C}} \\
& \eta=\frac{P / S_{t}}{G}
\end{aligned}
$$

Where G equals the irradiance (W/m2), St equals the array layer ( $\mathrm{m} 2$ ), and $\mathrm{P}$ equals the device power at the target point (W). Use that indexing relationship to measure the output power in shadow mode, temperature shifts, dust fall, light reflection and solar activity on the solar array. Excel 2019 and Design Expert 7 and Minitab 18 were included. The optimal power system was validated using the Taguchi and Response Surface Methodology (RSM). Flexible solar panels are connected in series and off-grid from the mains with battery backup. Climatic data for the 27-day test was collected from the Meteorological Station and direct measurement instruments linked to the LabVIEW program. Table (1) shows the test factors and surfaces in the Taguchi and RSM designs. For this test, 4 variables were chosen: irradiance power at three levels, temperature, wind speed, and flexibility at 3 levels. The Taguchi test design and RSM method were analyzed based on maximum power generation capacity. Modeling in this test is evaluated based on the criterion "more power is better".

By analyzing the model's components, engineering economics will decide the rejection or acceptance of a project. COMFAR software has been used in this research, with the complexity of the system's economic variables and technological variables. The present value of costs is calculated analogously that of the benefits. The difference is that for this figure, the outflows are considered as representing costs, rather than the inflows. BCR is calculated by Equation (3).

$$
B C R=\frac{\mid P V[\text { Benefits }] \mid}{\mid P V[\text { cost }] \mid}
$$

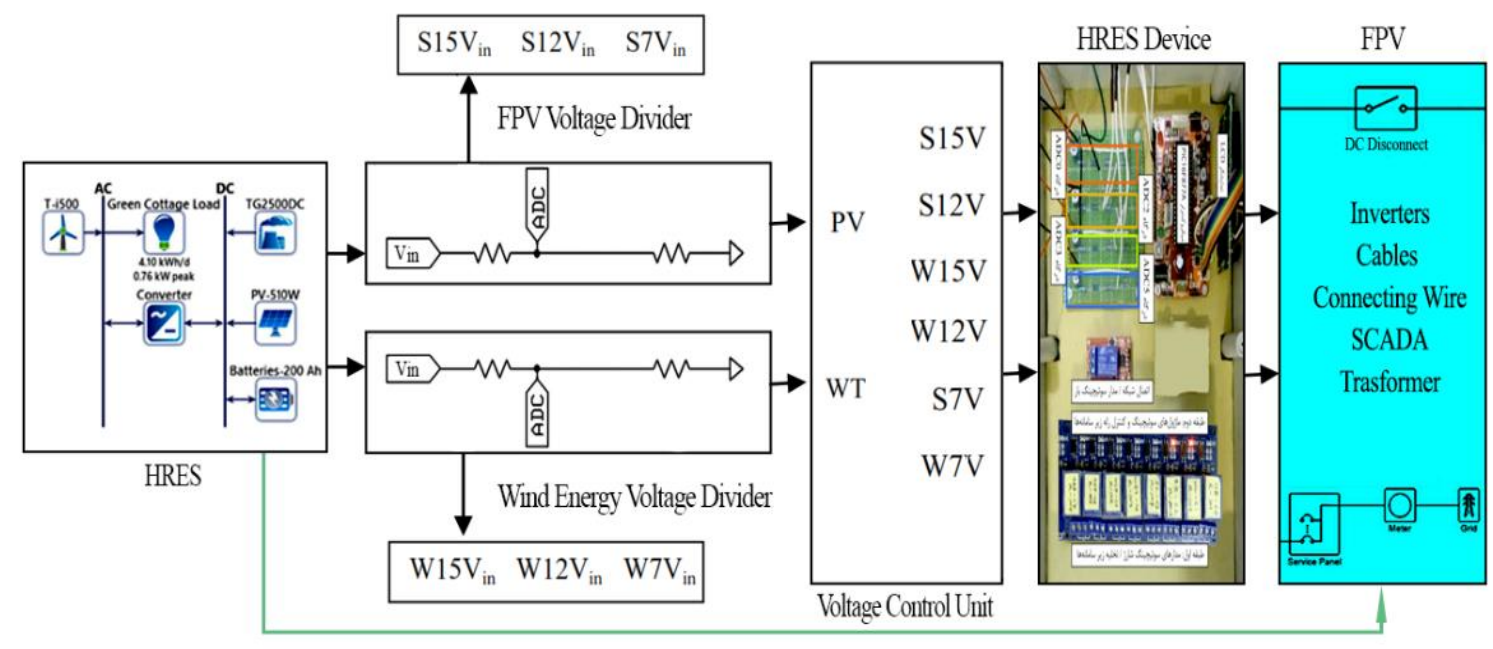

Fig.1 Hybrid renewable energy system components. 


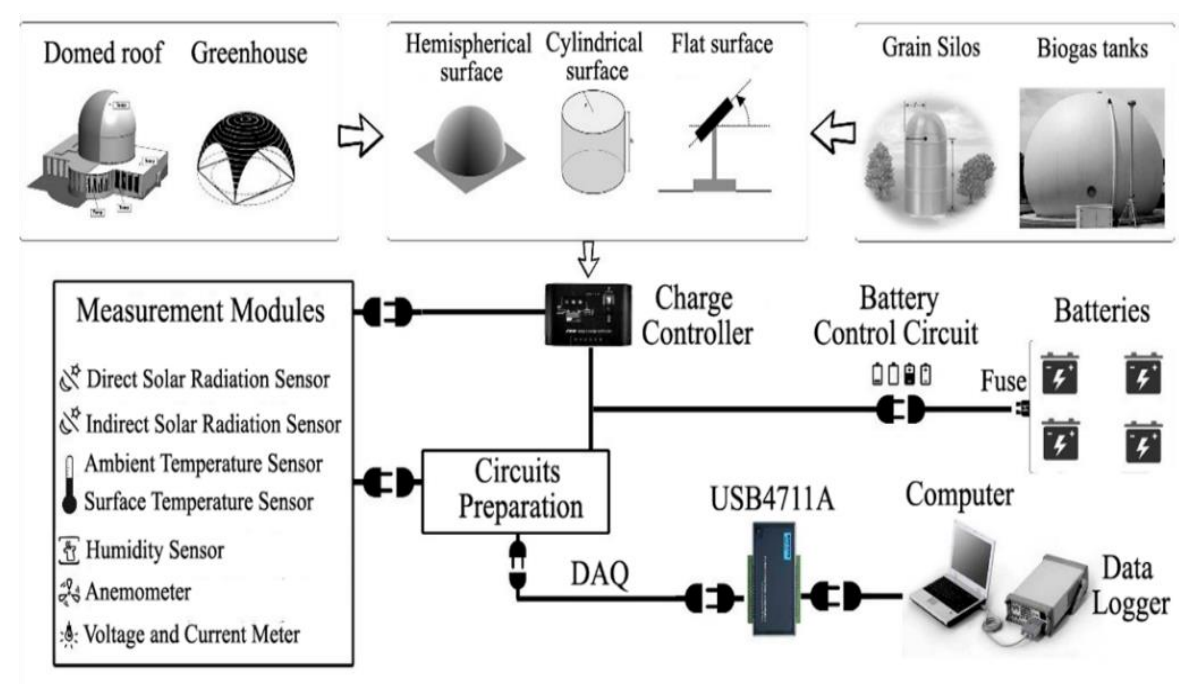

Fig.2 Flexible solar device and monitoring devices.

Table 1

Levels and responses of Taguchi and RSM design.

\begin{tabular}{llllllll}
\hline \multirow{2}{*}{ Factor } & \multirow{2}{*}{ Variables } & \multirow{2}{*}{ Units } & \multicolumn{3}{c}{ Taguchi } & \multicolumn{2}{c}{ RSM } \\
\cline { 4 - 8 } & & & Level 1 & Level 2 & Level 3 & Low Actual & High Actual \\
\hline A & Irradiance & $\mathrm{W} / \mathrm{m}^{2}$ & $200-500$ & $500-800$ & $800-1100$ & 200 & 1100 \\
$\mathrm{~B}$ & Temperature & ${ }^{\circ} \mathrm{C}$ & $20-30$ & $30-40$ & $40-50$ & 20 & 50 \\
$\mathrm{C}$ & Wind Speed & $\mathrm{m} / \mathrm{s}$ & $0-1$ & $1-2$ & $2-3$ & 0 & 3 \\
$\mathrm{D}$ & Flexibility & Degree & Flat & Cylinder & Sphere & 0 & п \\
\hline
\end{tabular}

Table 2

Green cottage electric consumers (Leonard et al., 2018).

\begin{tabular}{lllll}
\hline Section & Consumption (W) & Current (A) & ON-Time (Hours) & Ampere Hourly (Ah) \\
\hline Cooking & $40-800$ & 8.33 & 1 & 8.33 \\
Entertainment & $17-100$ & 2.5 & 2 & 5 \\
Lighting & $5-10$ & 2.28 & 5 & 11.45 \\
Computer & 50 & 4.16 & 8 & 33.28 \\
Maintenance & $20-100$ & 3.33 & 24 & 79.9 \\
Total & $132-1060$ & 20.6 & - & 137.96 \\
\hline
\end{tabular}

Internal rate of return (IRR) is a well-known criterion in terms of projects' economic evaluation. The deposit interest rate in Iran has freshly reduced to $15 \%$. However, in the last 10 years, it has equated to $16.7 \%$, regarded as the benchmark discount rate. According to the Iranian parliament's legislation, each kilowatt of renewable electricity is purchased from the consumer at $\sim 0.05 \$ / \mathrm{kWh}$. This price is supposed to be 20 years of the solar system's useful lifetime (Esmaeili Shayan \& Hojati, 2021). In (Esmaeili Shayan, Esmaeili Shayan, et al., 2021) the different feed-in tariff (FiT) rate is considered to be 0.05 $\$ / \mathrm{kWh}$. In addition, the project's NPV is set to zero and the discount rate, which is the same as the project's IRR, is determined. The calculation of the IRR is based on the NPV which can be expressed as a function of the IRR. Equation (4) uses cash flows at regular intervals for the calculation of IRR.
$I R R=\frac{C F_{i}}{(1+r)^{i}}-C_{i n v}$

Where $C F_{i}$ is cash flow in the period, $r$ is the discount rate, $i$ is time period and $C_{i n v}$ is initial investment. IRR calculate by COMFAR through trial and error because you are trying to arrive at whatever rate which makes the NPV equal to zero. The lifetime of the system is 20 years. The green cottage's electric customers are listed in Table (2).

\section{Results and Discussion}

JPsolar3W-12V flexible solar arrays generate flexible solar energy systems by fitting them to flat, cylindrical, and hemispheric base surfaces. The shape of I-V curve 
changes with the change in Fill Factor of solar cell which has been shown in Fig. 3. The minimum values of $\mathrm{FF}$ were calculated as 0.73 for the flat surface and 0.88 and 0.84 for the cylindrical and hemispherical surfaces, respectively. When the radiation is at level one, the device will begin to operate. Irradiance ranges between $400 \mathrm{~W} / \mathrm{m}^{2}$ and 600 $\mathrm{W} / \mathrm{m}^{2}$; then, the effectiveness is a little diminished, but it is still optimal for the system and satisfies the objective. More than $1000 \mathrm{~W} / \mathrm{m}^{2}$ of irradiance will have a negative impact on system performance. With an overall view of the irradiance power and the SNR band, it can be shown that irradiance intensity may substantially affect the function of the electrical power generation capacity through distancing itself from the center line and high failure.

The temperature in the latter group and the temperature level (3) had the most significant impact on the performance of the solar energy device. Incoming wind speed from level (1) to level (2) was useful for the subsystem and could change the conditions to produce power at extremely high temperatures. Flexibility or angles of the photovoltaic solar panels has shown that the change in this element, including the usage of the system in flat style (level 1) or when installed on a spherical surface (level 2) or on a cylindrical surface (level 3), may affect the production of the full power objective. The system angle group and the SNR revealed that level (1) defined as the flat surface layer might significantly affect the solar system. The application of the system at level (2), i.e. the application of the system to the spherical surface, considering its proximity to the middle power line goal, is more efficient than the levels (1) and (3). Level (3) indicated that the application of the method to a cylindrical surface is more efficient than a flat surface, but the optimum output is at level (2). The use of the process on the roof in flat styles, such as bitumen, is therefore not taken priority. When a system needs both grain silos and biogas reservoirs in a farm simultaneously, the operation of the device under these conditions would be superior to the hemisphere level, which implies the biogas reservoir.

The largest effect on the function of the flexible photovoltaic system, is related to the rate of irradiance, wind speed, temperature, and use on various such as flat, cylindrical and spherical materials. In the present experiment, Taguchi's study found that if the device were evaluated at chosen levels based on the optimal manufacturing process and variables, it would be possible to predict a combined power of $49.9 \mathrm{~W}$ with $\mathrm{SNR}=33.929$. If the function is measured separately and on a fully flat surface strength of the function, it would be equal to $53.3 \mathrm{~W}$ with SNR = 34.4918. When the model was used to calculate the power on the cylindrical level, the device's power was equal to $54.05 \mathrm{~W}$ with $\mathrm{SNR}=34.6368$; for the hemispheric level, the corresponding power of $55.7 \mathrm{~W}$ with $\mathrm{SNR}=$ 34.8880 was measured. The choice of the hemispheric surface is then classified into first and second-level cylinder points. According to the Taguchi experiments, the dynamic conditions applied to the flexible solar system indicate the ideal conditions for the use of a flexible panelbased solar conversion system.

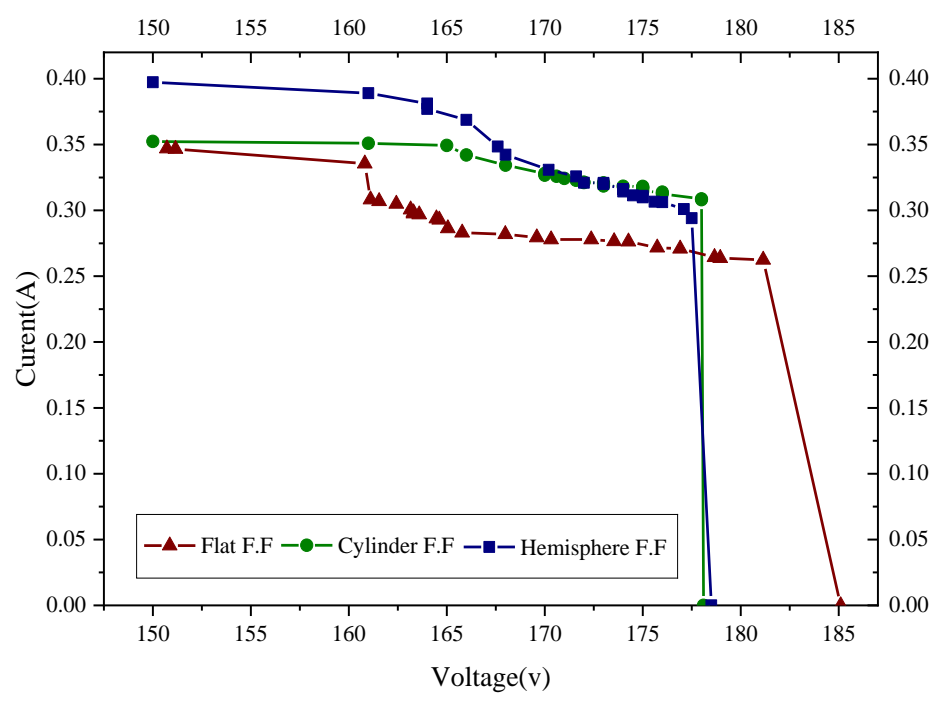

Fig 3. I-V Curve modification with varying FF.

Table 3

List of solar power production costs in systems at different surfaces.

\begin{tabular}{ccc}
\hline Systems & Power Production $(\mathrm{kWh} . \$)$ & Total Revenue Per Year $(\$)$ \\
\hline Flat & $810.369 \times 0.05$ & 40.518 \\
Cylinder & $960.124 \times 0.05$ & 48.006 \\
Hemispherical & $1000.165 \times 0.05$ & 50.008 \\
\hline
\end{tabular}


The systems' production capacity is calculated over a period of a year. Performance-based flexible systems at their maximum power production conditions can have other revenues when deployed on different surfaces, according to Table 3. The flat surface system produced $810.369 \mathrm{kWh}$, the cylindrical surface $960.124 \mathrm{kWh}$, and the hemisphere surface $1000.165 \mathrm{kWh}$. Total Revenue Per Year can be calculated for each system if the feed-in tariff is set at $\$ 0.05$ Per $\mathrm{kWh}$.

Therefore, 56 watts is equal to $\$ 44.8$ in 2020(Ghasemzadeh et al., 2020). Thin-film technology has always been cheaper but less efficient than conventional cSi technology. However, it has significantly improved over the years(Esmaeili Shayan et al., 2020). The total cost of a flexible photovoltaic system including the purchase of panels, installation costs, etc. is estimated at $\$ 181.78$ according to the standard in current photovoltaic projects. Unforeseen costs included glue costs for reposing panels to surfaces, maintenance costs, and soil cleaning. The 20-year maintenance life of the solar system was estimated at $\$ 20$ per year. Sensitivity analysis is a calculation procedure that predicts the effects of changes on input data. Investment decisions are wracked with uncertainty and risk. As seen in Fig. 4, The irradiance peak is reached $1067.1 \mathrm{~W} / \mathrm{m}^{2}$.

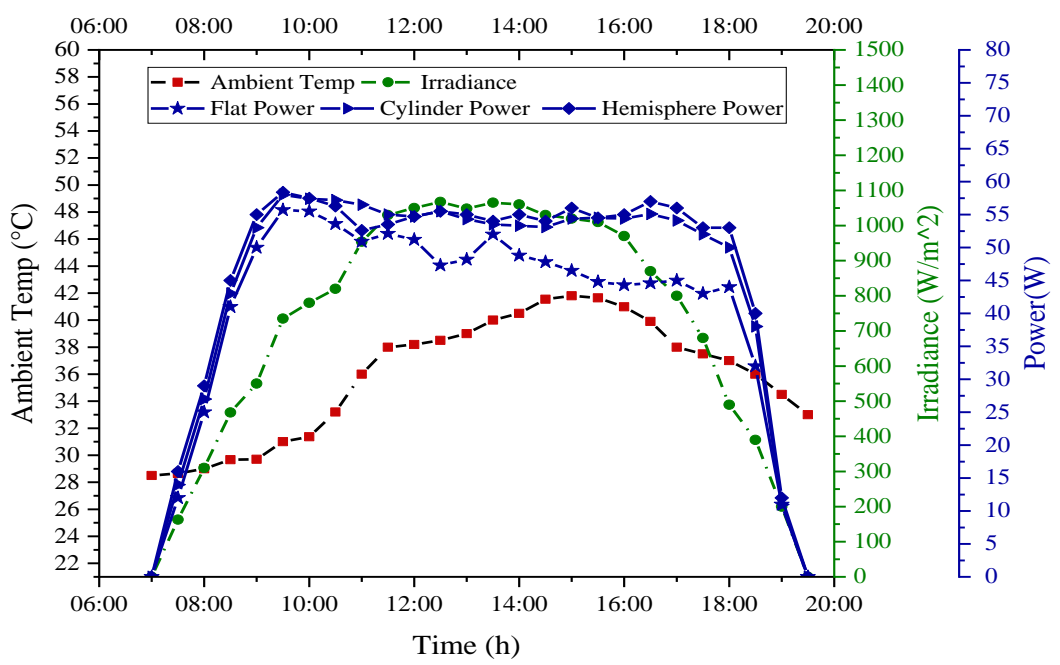

Fig 4. System factors and power analysis.

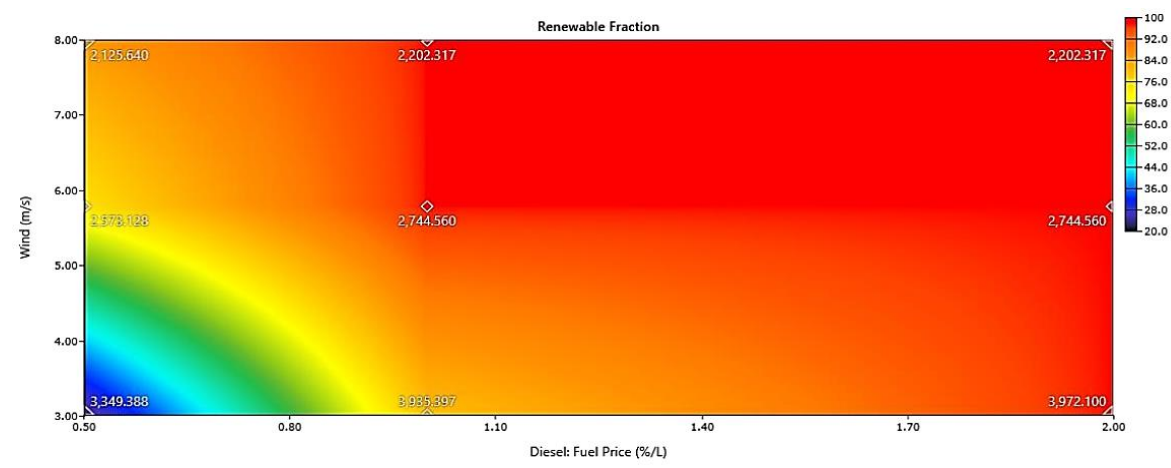

A: The system optimization

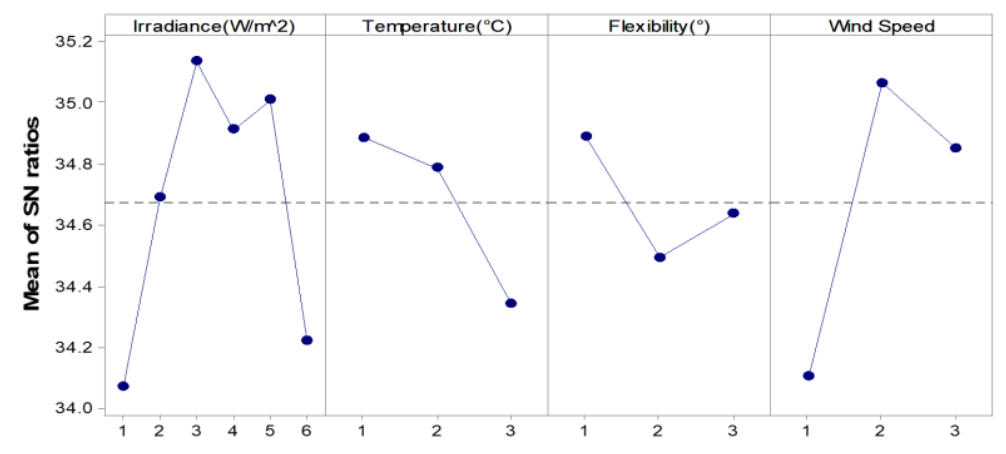

Signal-to-noise: Larger is better

B: The Taguchi Signal-to-Noise ratio

Fig 5. The system optimization and effect of test variables in the real-time system modeling. 
In the cylinder, one side of the shadow and one side of the irradiance are usually present. For at least 3 hours, the irradiance will be greater than $735 \mathrm{~W} / \mathrm{m}^{2}$. It is likewise at its peak in the middle of the day. At sunset, the irradiance will be at its lowest and will finally hit zero. After sunrise, the irradiance power on the south side of the test cylinder increased with a gentle slope, reaching a maximum of 1048 $\mathrm{W} / \mathrm{m}^{2}$ in the afternoon (around 14:00). These adjustments regulated the form of curved surfaces like the Sin Type. Power in the hemisphere increased after sunrise and reached a maximum of $58.4 \mathrm{~W}$ at the beginning of the day. At midday (from 09:30 to 17:30), the power potential was almost constant at the hemispherical and cylindrical surface and was within the standard line range $(55.5 \mathrm{~W})$. Then, as the shade increases and the intensity of the light falls, the power decreases to zero.

The maximum power in Taguchi Method Test is related to the system deployment on the cylinder facade and is equal to $59.87 \mathrm{~W}$, while the minimum power of $57.84 \mathrm{~W}$ is related to the system when deployed on the flat surface, and maximum power in RSM Test is relevant to the system deployment on the hemispherical $(\mathrm{H})$ surface and equal to $61.14 \mathrm{~W}$ and minimum power of system is $56.6 \mathrm{~W}$ when related to the extent on the flat surface. The system's performance (SP) under standard test conditions (STC) (25 ${ }^{\circ} \mathrm{C}$ and irradiance power of $1000 \mathrm{~W} / \mathrm{m}^{2}$ ) and in the laboratory for deploying on the cylinder and hemispherical facades has been measured $7.45 \%$. The minimum performance was measured at $7.09 \%$ and related to the flat surface. In the model analysis, the open-circuit voltage at the flat system level was equal to 185.7 volts and the shortcircuit current reached 0.347 in the most optimum scenario. Furthermore, the maximum production current was 0.36 amps when the system was deployed on the hemispherical surface. Therefore, the system in the case of deployment on the hemispherical surface by receiving diffusion irradiances and vertical irradiances has optimal electrical and quality characteristics compared to other deployment surfaces. The second and third priorities are related to the cylindrical and flat surfaces, respectively.

This study has shown that using an experimental design of Taguchi and RSM can explain the big data of solar energy systems. When the actual test data in these models will verify the correct orientation of the model. Fig. 5 shows real-time system modeling. The system optimization revealed that by assuming an average wind speed of $3 \mathrm{~m} / \mathrm{s}$, eliminating the diesel generator, using three batteries, and increasing the capacity of the solar and wind subsystems, the cost of renewable energy production may be decreased to $\$ 0.402 \mathrm{kWh}$.

The impact of test factors on system power is shown in Fig.5B. The irradiance and wind speed factors have a positive effect on the system power, whereas the temperature factor has a negative impact. the optimum power in the cylindrical surface is 60.27 watts, once the ambient temperature is about $36^{\circ} \mathrm{C}$ and radiation is 1050 $\mathrm{W} / \mathrm{m}^{2}$, and the wind speed is zero, and the humidity is equal to $48.1 \%$. Sensitivity analysis is performed to predict the future. Fig. 6 shows the sensitivity analysis of systems. The most sensitive parameters Sales revenue and on the flat surface and then Increase in fixed assets has a more significant impact on IRR. The investment attractiveness and IRR share of the flexible photovoltaic system are related to its use on flat, cylindrical, and hemisphere surfaces, respectively.

The economic findings show that the NPV of the flexible solar energy system at $16.70 \%$, when applied at level 1 , is $\$ 697.52$ and that the IRR is $34.81 \%$ and the capital return duration is 8.58 years. This amount is increased to $\$ 900.88$ in cylindrical surfaces and $\$ 955.18$ in hemispheres. The rate of return on investment was $39.29 \%$ at the cylindrical level and $40.47 \%$ at the hemisphere. In the flat-surface production method, a $20 \%$ rise in project budget raised the internal yield by $21.3 \%$ and a $20 \%$ fall in sales. The project's internal rate of return would be reduced by $23 \%$. Flexible solar systems installed on cylindrical and hemispheric surfaces with a $20 \%$ rise in project prices, with the IRR rising by $25.59 \%$ and $24.48 \%$, respectively. During the production time and deployment of flexible solar systems, the net flows were negative and when installed on cylindrical and hemispheric surfaces, from 7.20 years and 6.90 years to the end of the design period, the total net product flows were positive and constantly expanding. The description of the results is listed in Table 4.

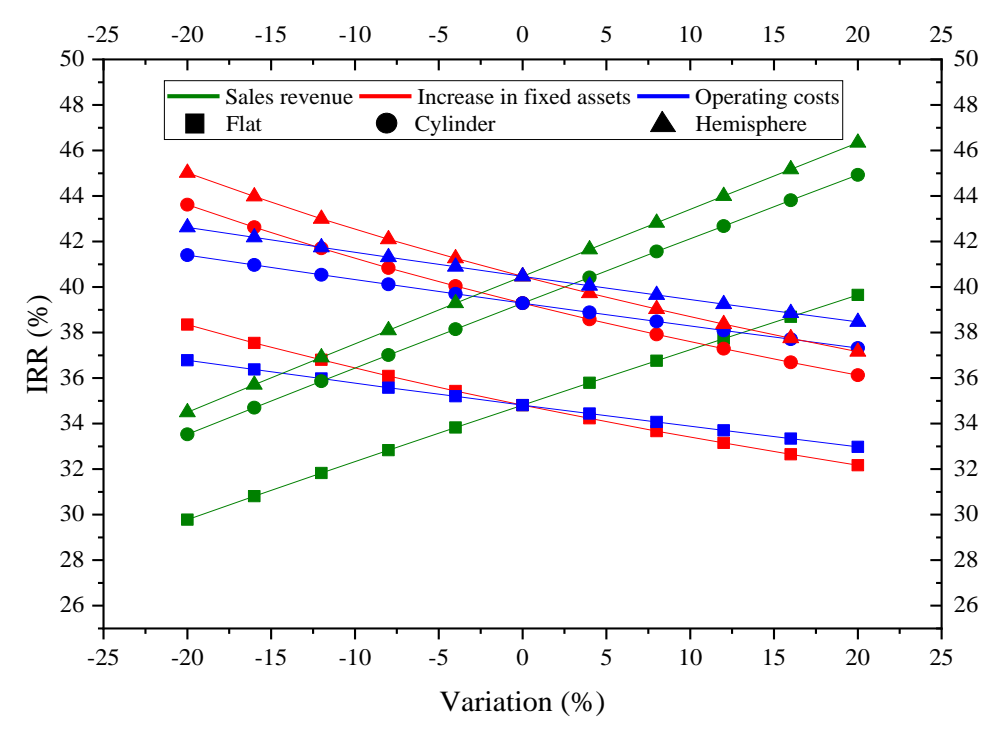

Fig 6. Effect of test variables on system power production quality in the actual test 
Table 4

Systems behavioral assessment for more is great target

\begin{tabular}{|c|c|c|c|c|c|c|c|c|}
\hline Power Plan & MP Taguchi (W) & MP RSM (W) & FF (\%) & S.P (\%) & $\mathrm{OCV}(\mathrm{V})$ & $\mathrm{SCC}(\mathrm{A})$ & IRR & NPV \\
\hline Flat S. & 57.84 & 56.6 & 73 & 7.1 & 185 & 0.34 & 34.8 & 697.5 \\
\hline Cylindrical S. & 59.87 & 57.71 & 88 & 7.4 & 179 & 0.35 & 39.2 & 900.8 \\
\hline Hemisphere S. & 58.27 & 61.14 & 84 & 7.4 & 178 & 0.36 & 40.4 & 955.1 \\
\hline
\end{tabular}

\section{Conclusions}

This project investigates a flexible solar panel for energy on curved surfaces. We employed the actual capability of flexible solar energy conversion in this study, which was conducted utilizing environmental evaluation and environmental techniques centered on pilot projects. Annual energy production on the flat surface was $810 \mathrm{kWh}$, cylindrical surface $960 \mathrm{kWh}$, and hemisphere surface 1000 $\mathrm{kWh}$. This shows that the findings were valid concerning RSM analysis. The system output current was limited to 0.36 amps when deployed on the hemispherical surface. Using Taguchi methods, research revealed that the influence of power production factors was surface temperature, irradiation, ambient temperature, wind, and humidity. The economic results indicate that NPV at Flat surface is $\$ 697.52$, with an IRR of $34.81 \%$ and a capital return term of 8.58 years. Cylindrical surfaces and hemispheres each see an increase of $\$ 955.18$. The investment yield returned $39.29 \%$ for cylindrical structures and $40.47 \%$ for spherical structures. Consequently, the order of economy in the systems would also be connected to a compact solar system installed on hemispheric, cylindrical and flat surfaces. The following can be stated as a general conclusion. In order to minimize the temperature decrease, the device must be mounted in place of the wind blinds. Radiation and temperature levels are higher than normal. A sensitivity analysis was performed to verify the economic analysis. The Pareto analysis introduces variables that affect system performance, but it is recommended to conduct on-site analysis of similar systems and compare the results during seasonal periods. It is proposed that modular systems be used in flags, towers, conventional structures, biogas tanks, grain storage silos, etc. It is preferable to install electrical systems on one side of the building, which is the largest average of shade. It is recommended that compact structures be used in regions similar to the equator and desert zones.

\section{Nomenclatures}

$\begin{array}{ll}\text { Symbols } & \\ A & \text { Area (m2) } \\ C_{c f} & \text { Net Annual Cash Flow (\$) } \\ C F_{i} & \text { Cash Flow in the Time Period (\$) } \\ C_{i n v} & \text { Initial Investment (\$) } \\ F & \text { Flexibility (Degree) } \\ F F & \text { Fill Factor (\%) } \\ F i T & \text { Feed in Tariff }\left(\$ . \mathrm{kWh}^{-1}\right) \\ G & \text { Irradiance }\left(\mathrm{W} \cdot \mathrm{m}^{-2}\right) \\ I & \text { Current }(\mathrm{A}) \\ I R R & \text { Internal Rate of Return }(\%) \\ N C F_{i} & \text { Net Cash Flow for Period i }(\$) \\ N P V & \text { Net Present Value (\$) } \\ P & \text { Power (W) } \\ r & \text { Discount Rate }(\%) \\ S t & \text { Array Layer }\left(\mathrm{m}^{2}\right) \\ S / N & \text { Signal to Noise }(\mathrm{dB}) \\ T & \text { Temperature }\left({ }^{\circ} \mathrm{C}\right) \\ t & \text { Time (s) }\end{array}$

V

Greek Symbols

$\eta$

Subscript

$\mathrm{mmp} \quad$ Maximum Power Point

sc Short Circuit Current

oc

Open Circuit Voltage

Abbreviations

a-Si

BCR

BIPV

BOS

c-Si

FPVS

GHG

PBP

PV

RSM

SNR

STC

\author{
Amorphous Silicon \\ Benefit Cost Ratio \\ Built Integrated Photovoltaic \\ Balance of System \\ Crystalline Silicon \\ Flexible Photovoltaic Systems \\ Greenhouse Gases \\ Payback Period \\ Photovoltaic \\ Response Surface Methodology \\ Signal to Noise Ratio \\ Standard Test Conditions
}

\section{References}

Abdolbaqi, M. K., Azmi, W. H., Mamat, R., Mohamed, N. M. Z. N., \& Najafi, G. (2016). Experimental investigation of turbulent heat transfer by counter and co-swirling flow in a flat tube fitted with twin twisted tapes. International Communications in Heat and Mass Transfer, C(75), 295-302. doi: 10.1016/J.ICHEATMASSTRANSFER.2016.04.021

Al-Falahi, M. D. A., Jayasinghe, S. D. G., \& Enshaei, H. (2019). Hybrid algorithm for optimal operation of hybrid energy systems in electric ferries. Energy, 187, 115923. doi: 10.1016/J.ENERGY.2019.115923

Awad, O. I., Ali, O. M., Mamat, R., Abdullah, A. A., Najafi, G., Kamarulzaman, M. K., Yusri, I. M., \& Noor, M. M. (2017). Using fusel oil as a blend in gasoline to improve SI engine efficiencies: A comprehensive review. Renewable and Sustainable Energy Reviews, 69, 1232-1242. doi: 10.1016/J.RSER.2016.11.244

Azadbakht, M., Shayan, M. E., Jafari, H., Ghajarjazi, E., \& Kiapei, A. (2015). Factor Resistance Comparison of a Long Shaft in 955 and 1055 John Deere Grain Combine. doi: 10.5281/ZENODO.1100909

Azadbakht, M., Esmaeilzadeh, E., \& Esmaeili-Shayan, M. (2015). Energy consumption during impact cutting of canola stalk as a function of moisture content and cutting height. Journal of the Saudi Society of Agricultural Sciences, 14(2), 147-152. doi: 10.1016/j.jssas.2013.10.002

Azadbakht, M., Shayan, M. E., \& Jafari, H. (2013). Investigation of Long Shaft Failure in John Deere 955 Grain Combine Harvester under Static Load. Universal Journal of Agricultural Research, 1(3), 70-73. doi: 10.13189/UJAR.2013.010305

Bloem, J. J. J., Lodi, C., Cipriano, J., \& Chemisana, D. (2012). An outdoor Test Reference Environment for double skin applications of Building Integrated PhotoVoltaic Systems. Energy and Buildings, 50, 63-73. doi: 10.1016/j.enbuild.2012.03.023

Braito, M., Flint, C., Muhar, A., Penker, M., \& Vogel, S. (2017). Individual and collective socio-psychological patterns of photovoltaic investment under diverging policy regimes of 
Austria and Italy. Energy Policy, 109, 141-153. doi: 10.1016/J.ENPOL.2017.06.063

Briguglio, M., \& Formosa, G. (2017). When households go solar: Determinants of uptake of a Photovoltaic Scheme and policy insights. Energy Policy, 108, 154-162. doi: 10.1016/J.ENPOL.2017.05.039

Chen, J., E, J., Kang, S., Zhao, X., Zhu, H., Deng, Y., Peng, Q., \& Zhang, Z. (2019). Modeling and characterization of the mass transfer and thermal mechanics of the power lithium manganate battery under charging process. Energy, 187, 115924. doi: 10.1016/J.ENERGY.2019.115924

Dehghan, M., Rahgozar, S., Pourrajabian, A., Aminy, M., \& Halek, F. S. (2021). Techno-economic perspectives of the temperature management of photovoltaic (PV) power plants: A case-study in Iran. Sustainable Energy Technologies and Assessments, 45, 101133. doi: 10.1016/j.seta.2021.101133

Esmaeili Shayan, M. (2020). Solar Energy and Its Purpose in NetZero Energy Building. In A. Pérez-Fargallo \& I. OropezaPerez (Eds.), Zero-energy Buildings. New approaches and technologies. IntechOpen. doi: 10.5772/intechopen.93500

Esmaeili Shayan, M., Esmaeili Shayan, S., \& Nazari, A. (2021). Possibility of supplying energy to border villages by solar energy sources. Energy Equipment and Systems, 9(3), 279289. doi: 10.22059/EES.2021.246079

Esmaeili Shayan, M., \& Ghasemzadeh, F. (2020). Nuclear Power Plant or Solar Power Plant. In N. Awwad (Ed.), Nuclear Power Plants - The Processes from the Cradle to the Grave. Landon: IntechOpen. doi: 10.5772/intechopen.92547

Esmaeili Shayan, M., \& Hojati, J. (2021). Floating Solar Power Plants: A Way to Improve Environmental and Operational Flexibility. Iranian (Iranica) Journal of Energy \& Environment, $\quad 0 . \quad$ Retrieved from http://www.ijee.net/article_140620.html

Esmaeili shayan, M., Najafi, G., \& Gorjian, S. (2020). Design Principles and Applications of Solar Power Systems (In Persian) (First Edit). Tehran: ACECR PublicationAmirkabir University of Technology Branch.

Esmaeili Shayan, M., Najafi, G., \& Lorenzini, G. (2022). Phase change material mixed with chloride salt graphite foam infiltration for latent heat storage applications at higher temperatures and pressures. International Journal of Energy and Environmental Engineering 2021, 1-11. doi: 10.1007/S40095-021-00462-5

Esmaeili Shayan, M., Najafi, G., \& Nazari, A. (2021). The Biomass Supply Chain Network Auto-Regressive Moving Average Algorithm. International Journal of Smart Grid IjSmartGrid, 5(1), 15-22. Retrieved from https://www.ijsmartgrid.ijrer.org/index.php/ijsmartgridnew/ article/download/153/pdf

Ettefaghi, E., Ghobadian, B., Rashidi, A., Najafi, G., Khoshtaghaza, M. H., Rashtchi, M., \& Sadeghian, S. (2018). A novel bio-nano emulsion fuel based on biodegradable nanoparticles to improve diesel engines performance and reduce exhaust emissions. Renewable Energy, 125, 64-72. doi: 10.1016/j.renene.2018.01.086

Ghasemzadeh, F., Esmaeilzadeh, M., \& Esmaeili shayan, M. (2020). Photovoltaic Temperature Challenges and Bismuthene Monolayer Properties. International Journal of Smart Grid, 4(4), 190-195. Retrieved from https://www.ijsmartgrid.org/index.php/ijsmartgridnew/articl e/view/131/pdf

Ghritlahre, H. K., \& Prasad, R. K. (2018). Application of ANN technique to predict the performance of solar collector systems - A review. Renewable and Sustainable Energy Reviews, 84(December 2017), 75-88. doi: 10.1016/j.rser.2018.01.001

Hasanien, H. M. (2018). Performance improvement of photovoltaic power systems using an optimal control strategy based on whale optimization algorithm. Electric Power Systems Research, 157, 168-176. doi: 10.1016/j.epsr.2017.12.019

IEA. (2021). Global Energy Review 2021 - Analysis - IEA. Retrieved from https://www.iea.org/reports/global-energyreview-2021
Jäger-Waldau, A. (2021). Overview of the Global PV Industry. Reference Module in Earth Systems and Environmental Sciences. doi: 10.1016/B978-0-12-819727-1.00054-6

Padmanathan K., Govindarajan, U., Vigna K., Selvi T, S., Jeevarathinam, B. (2018). Integrating solar photovoltaic energy conversion systems into industrial and commercial electrical energy utilization-A survey. Journal of Industrial Information Integration. doi: 10.1016/j.jii.2018.01.003

Keshtegar, B., Mert, C., \& Kisi, O. (2018). Comparison of four heuristic regression techniques in solar radiation modeling: Kriging method vs RSM, MARS and M5 model tree. Renewable and Sustainable Energy Reviews, 81(July 2017), 330-341. doi: 10.1016/j.rser.2017.07.054

Leonard, M. D., \& Michaelides, E. E. (2018). Grid-independent residential buildings with renewable energy sources. Energy, 148, 448-460. doi: 10.1016/J.ENERGY.2018.01.168

Liobikienè, G., \& Butkus, M. (2021). Determinants of greenhouse gas emissions: A new multiplicative approach analysing the impact of energy efficiency, renewable energy, and sector mix. Journal of Cleaner Production, 309, 127233. doi: 10.1016/J.JCLEPRO.2021.127233

Mat Yasin, M. H., Mamat, R., Najafi, G., Ali, O. M., Yusop, A. F., \& Ali, M. H. (2017). Potentials of palm oil as new feedstock oil for a global alternative fuel: A review. Renewable and Sustainable Energy Reviews, 79, 1034-1049. doi: 10.1016/J.RSER.2017.05.186

Mohammadi, M., Ghasempour, R., Razi Astaraei, F., Ahmadi, E., Aligholian, A., \& Toopshekan, A. (2018). Optimal planning of renewable energy resource for a residential house considering economic and reliability criteria. International Journal of Electrical Power \& Energy Systems, 96, 261-273. doi: 10.1016/J.IJEPES.2017.10.017

Muhammad-Sukki, F., Ramirez-Iniguez, R., Abu-Bakar, S. H., McMeekin, S. G., \& Stewart, B. G. (2011). An evaluation of the installation of solar photovoltaic in residential houses in Malaysia: Past, present, and future. Energy Policy, 39(12), 7975-7987. doi: 10.1016/J.ENPOL.2011.09.052

Najafi, G., \& Ghobadian, B. (2011). LLK1694-wind energy resources and development in Iran. Renewable and Sustainable Energy Reviews, 15(6), 2719-2728. doi: 10.1016/J.RSER.2011.03.002

Najafi, G., Ghobadian, B., Yusaf, T., \& Rahimi, H. (2007). Combustion analysis of a CI engine performance using waste cooking biodiesel fuel with an artificial neural network aid. American Journal of Applied Sciences, 756-764.

O'Shaughnessy, E., Cruce, J., \& Xu, K. (2021). Rethinking solar PV contracts in a world of increasing curtailment risk. Energy Economics, 98, 105264. doi: 10.1016/J.ENECO.2021.105264

Rabab Mudakkar, S., Zaman, K., Shakir, H., Arif, M., Naseem, I., \& Naz, L. (2013). Determinants of energy consumption function in SAARC countries: Balancing the odds. Renewable and Sustainable Energy Reviews, 28, 566-574. doi: 10.1016/J.RSER.2013.08.006

Salehi-Isfahani, D., \& Mostafavi-Dehzooei, M. H. (2018). Cash transfers and labor supply: Evidence from a large-scale program in Iran. Journal of Development Economics, 135, 349-367. doi: 10.1016/J.JDEVECO.2018.08.005

Shukla, A. K., Sudhakar, K., Baredar, P., \& Mamat, R. (2018). BIPV based sustainable building in South Asian countries. Solar Energy, 170, 1162-1170. doi: 10.1016/j.solener.2018.06.026

Skordoulis, M., Ntanos, S., \& Arabatzis, G. (2020). Socioeconomic evaluation of green energy investments: Analyzing citizens' willingness to invest in photovoltaics in Greece. International Journal of Energy Sector Management, 14(5), 871-890. doi: 10.1108/IJESM-12-2019-0015/FULL/XML

Solangi, H., Islam, M.R., Saidur, R., Rahim, N.A., Fayaz, H. (2011). A review on global solar energy policy, Renewable and Sustainable Energy Reviews. doi: 10.1016/j.rser.2011.01.007

Tsantopoulos, G., Arabatzis, G., \& Tampakis, S. (2014). Public attitudes towards photovoltaic developments: Case study from Greece. Energy Policy, 71, 94-106. doi: 10.1016/J.ENPOL.2014.03.025 
Citation: Esmaeili Shayan, M., Najafi, G., Ghobadian, B., Mazlan, M. (2022) Sustainable Design of a Near-Zero-Emissions Building Assisted by a Smart Hybrid Renewable Microgrid. International Journal of Renewable Energy Development, 11(2), 471-480, doi: 10.14710/ijred.2022.43838

480 ।

Yan, J., Luo, G., Xiao, B., Wu, H., He, Z., \& Cao, Y. (2015). Origin of high fill factor in polymer solar cells from semiconducting polymer with moderate charge carrier mobility. Organic Electronics, 24, 125-130. doi: 10.1016/J.ORGEL.2015.05.034

Yin, Y., Liu, T., \& He, C. (2019). Day-ahead stochastic coordinated scheduling for thermal-hydro-wind-photovoltaic systems. Energy, 187, 115944. doi: 10.1016/J.ENERGY.2019.115944
Zeb, R., Salar, L., Awan, U., Zaman, K., \& Shahbaz, M. (2014). Causal links between renewable energy, environmental degradation and economic growth in selected SAARC countries: Progress towards green economy. Renewable Energy, 71, 123-132. doi: 10.1016/J.RENENE.2014.05.012. 